\title{
Analysis of the first therapeutic-target-achieving time of warfarin therapy and associated factors in patients with pulmonary embolism
}

\author{
XIAOWEI GONG ${ }^{*}$, HAIYAN WANG ${ }^{*}$ and YADONG YUAN \\ Department of Respiratory Disease and Critical Care Medicine, The Second Hospital of Hebei Medical University, \\ Shijiazhuang, Hebei 050000, P.R. China
}

Received February 9, 2015; Accepted March 30, 2016

DOI: $10.3892 /$ etm.2016.3610

\begin{abstract}
The present study aimed to investigate the factors affecting the first therapeutic-target-achieving (TTA) time of warfarin therapy in patients with acute pulmonary embolism (PTE). Between January 2008 and June 2013, patients with PTE confirmed by transpulmonary arterial enhanced computed tomographic pulmonary angiography or pulmonary ventilation perfusion scanning were included in the present study. Data collected included demographic information, history of tobacco and alcohol intake, basic diseases (stable and unstable hypertension, diabetes, heart failure, cancer/cerebral infarction, old myocardial infarction and atrial fibrillation), liver and kidney function, the haemoglobin and platelet count of the blood, international normalized ratio monitoring, warfarin dosage adjustment and medication combinations. Dynamic changes in international normalized ratio, anticoagulant efficacy, and adverse events within 90 days were monitored and analyzed. Univariate analysis demonstrated that the following factors affect the first TTA time: Initial dose, body mass index (BMI), liver function, heart failure, and the administration of levofloxacin, cephalosporins, and blood circulation-activating drugs. Logistic regression analysis revealed that the following were independent factors of the first TTA time: Initial dose, BMI, liver function, heart failure and levofloxacin. Therefore, the results of the present study demonstrated that various factors may affect the first TTA time of warfarin therapy,
\end{abstract}

Correspondence to: Miss Yadong Yuan, Department of Respiratory Disease and Critical Care Medicine, The Second Hospital of Hebei Medical University, 215 Heping West Road, Shijiazhuang, Hebei 050000, P.R. China

E-mail: yadongyuancn@163.com

*Contributed equally

Key words: warfarin, first therapeutic-target-achieving time, influencing factors, international normalized ratio, pulmonary embolism including the initial dose, BMI, liver function, heart function and concomitant medication.

\section{Introduction}

Acute pulmonary embolism (PTE) remains one of the most common, life-threatening cardiovascular events. The proportion of hospitalized patients with PTE has gradually increased (1), although the fatality rate varies according to the hemodynamic status of the patient (2-4). Regardless of the elevated mortality and recurrence or other poor prognosis factors in patients with an unstable hemodynamic status, adequate anticoagulation remains an important aspect of PTE management.

Vitamin $\mathrm{K}$ antagonists have been used in traditional medicine as anticoagulants. The annual risk of bleeding for vitamin $\mathrm{K}$ antagonists is $1-3 \%$, and this value is not substantially reduced by treatment with newer oral anticoagulant therapy $(5,6)$. Furthermore, given their lower cost, vitamin $\mathrm{K}$ antagonists are popular with patients with venous thromboembolism/PTE. Warfarin, which is a vitamin $\mathrm{K}$ antagonist, is a common oral anticoagulant that is predominantly used for the prevention and treatment of various thromboembolic disease (7). In order to achieve anticoagulant efficacy, the anticoagulation intensity index-international normalized ratio (INR) of warfarin must be maintained between 2.0 and 3.0 in patients with PTE (8). Previous studies have suggested that achieving stable anticoagulation requires a number of weeks to months of treatment, with the INR maintained within the effective range in only $40-60 \%$ of patients, including those with a stable status $(9,10)$. Risk of bleeding or rethrombosis is increased during the remaining non-therapeutic-target-achieving (TTA) period, particularly in the initial treatment period (11-13). Therefore, rapidly achieving therapeutic INR may decrease the incidence of adverse reactions, ensure anticoagulation efficacy and reduce the duration and expense associated with heparin treatment. To date, a limited number of studies have investigated the first TTA time and relevant factors associated with warfarin therapy, including the initial anticoagulation indicators, safety indicators and anticoagulation efficacy. The present study aimed to investigate the correlation between the 
aforementioned factors and four different INR TTA time periods, in order to assess the first TTA time and associated factors of warfarin therapy in patients with PTE.

\section{Materials and methods}

Subjects. Between January 2008 and June 2013, patients were selected based on a diagnosis of PTE, which was confirmed by computed tomographic pulmonary angiography or pulmonary ventilation perfusion scanning, in accordance with the 'Pulmonary embolism diagnosis and treatment guidelines' issued by the Chinese Institute of Respiratory Medicine Branch (2001) (14). Inclusion criteria were as follows: i) Aged $\geq 18$ years, without a previous history of warfarin therapy, while achieving a therapeutic INR (target range, 2.0-3.0) within 90 days of warfarin administration; ii) anticoagulation maintenance therapy with warfarin for $\geq 3$ months; and iii) regular monitoring of INR values following discharge from the hospital. Exclusion criteria were as follows: i) Succumbed to the condition during hospitalization; ii) incomplete follow-up information; iii) failure to follow the prescribed treatment and monitoring; and iv) transfer to a different hospital for treatment. The present study was conducted with approval from the Ethics Committee of Hebei Medical University (Shijiazhuan, China), in accordance with the Declaration of Helsinki. Written informed consent was obtained from all participants.

Data collection. A total of 302 Chinese patients with PTE were enrolled in the present retrospective study. Patient information was collected, including demographic data, laboratory data, clinical data during hospitalization and health status within 90 days of commencing warfarin therapy. Demographic data included age, gender, height, weight and body mass index (BMI). Laboratory data included liver function, alanine aminotransferase, aspartate transaminase, albumin (ALB), serum creatinine, hemoglobin and coagulation analyses. Clinical data during hospitalization included basic diseases, tobacco and alcohol intake history, warfarin dose adjustment and medication. Following discharge, the patients were followed-up for 90 days in order to monitor dynamic changes in INR and associated warfarin dose adjustments, and to observe adverse reactions including bleeding, re-embolism and anticoagulant efficacy, (Garcia 2013, Ageno) which was scored as effective, improved or ineffective. Patients were divided into four groups according to their first TTA time: Group I, TTA time $\leq 7$ days; group II, 8 days $<$ TTA time $\leq 14$ days; group III, 15 days $<$ TTA time $\leq 28$ days; and group IV, TTA time $>28$ days. These groups were used in the analyses of the correlation between the various factors and the first TTA time.

The following pharmacological agents were used during the present study: Cefmenoxime hydrochloride (Tianjin Takeda Pharmaceutical Co., Ltd., Tianjin, China); cefazolin (Shiyao Pharmaceutical Group, Shijiazhuang, China); ceftriaxone-tazobactam (Haikou Kellett Pharmaceutical Co., Ltd., Hainan, China); levofloxacin lactate (Zhejiang Pharmaceutical Co., Ltd., Xinchang Pharmaceutical Factory, Zhejiang, China); Danhong (Heze Step Pharmaceutical Co., Ltd., Shandong, China); and Salvia tetramethylpyrazine injection (Guizhou Yi Bai Pharmaceutical Co., Ltd., Guizhou, China).
Research contents. Outcome measures for the anticoagulation therapy were as follows: i) First TTA time (in days) following the initiation warfarin therapy required to reach a therapeutic INR (target range, 2.0-3.0) for $\geq 2$ consecutive days; and ii) the proportion of INRs per TTA time period $(\%)$.

Safety indicators included adverse reactions such as minor or serious bleeding within 90 days of commencing warfarin therapy and rethrombosis.

Efficacy indicators included the rates of effective, improved and ineffective anticoagulation achieved within 90 days of commencing warfarin therapy.

Statistical analysis. The present study was a retrospective analysis and data were processed using SPSS 17.0 statistical software (SPSS, Inc., Chicago, IL, USA). Measurement data were expressed as the mean \pm standard deviation and counting data were expressed as rates. Independent sample t-test was used for the intergroup mean comparison, and analysis of variance was conducted for multi-group mean comparisons. The $\chi^{2}$ test was used for multi-rate comparison, and ordinal logistic regression was used for multivariate analysis. $\mathrm{P}<0.05$ was considered to indicate a statistically significant difference.

\section{Results}

Single factor analysis. A total of 302 patients with PTE were enrolled in the present study with a mean initial TTA time of $17.57 \pm 12.52$ days. The numbers of cases in the four INR TTA time segments were 68 (22.52\%), 80 (26.49\%), 108 (35.76\%), and $46(15.23 \%)$, respectively. Therefore, group III (TTA time, 15-28 days) was the most populated, followed by group II (TTA time, 8-14 days) (Table I).

Initial dose of warfarin. Among the 302 patients, the average doses of warfarin in the four INR TTA time segments were $3.59 \pm 0.92,3.10 \pm 0.29,2.66 \pm 0.23$ and $2.40 \pm 0.32 \mathrm{mg}$, respectively $(\mathrm{P}<0.001$; Table I). Statistical analysis of the initial three doses $(2.5,3$ and $5 \mathrm{mg})$ demonstrated that the most common TTA time of patients in the $2.5,3$ and $5 \mathrm{mg}$ groups was $15-28$ (44.14\%), 8-28 (60.25\%) and $\leq 7$ days (41.67\%), respectively $(\mathrm{P}=0.01$; Table II). These results demonstrated that the initial dose of warfarin was a factor that was capable of affecting the first TTA time (Fig. 1A) of patients in the present study.

Basic clinical characteristics. The most common TTA times of patients categorized via BMI as normal, overweight, degree I obese and degree II obese were $\leq 7$ (36.59\%), 15-28 (33.33\%), $15-28(43.90 \%)$ and $>28$ days (33.33\%), respectively $(\mathrm{P}<0.001)$. These results demonstrated that BMI affected the first TTA time (Fig. 1B) of patients in the present study, whereas age, gender, tobacco, and alcohol intake had no effect on the first TTA time (data not shown).

Basic diseases. The first TTA time was $<14$ days in $71.43 \%$ of patients with heart failure and $>14$ days in $64.24 \%$ of patients without heart failure $(\mathrm{P}<0.001$; Table II). Heart failure significantly affected the first TTA time (Fig. 1C) of patients enrolled in the present study, whereas hypertension, diabetes and malignant cancers had no effect on the first TTA time (data not shown). 
Table I. Univariate analysis of the first therapeutic-target-achieving time and body mass index.

\begin{tabular}{|c|c|c|c|c|c|}
\hline \multirow[b]{2}{*}{ Group } & \multicolumn{4}{|c|}{ Body mass index ${ }^{a}$} & \multirow{2}{*}{$\begin{array}{l}\text { Mean initial } \\
\text { dosage }(\mathrm{mg})^{\mathrm{b}}\end{array}$} \\
\hline & Normal & Overweight & Degree I obesity & Degree II obesity & \\
\hline I & $30(36.59)$ & $24(26.67)$ & $14(17.07)$ & $0(0.00)$ & $3.59 \pm 0.92$ \\
\hline II & $18(21.95)$ & $24(26.67)$ & $20(24.39)$ & $18(37.50)$ & $3.10 \pm 0.29$ \\
\hline III & $28(34.15)$ & $30(33.33)$ & $36(43.90)$ & $14(29.17)$ & $2.66 \pm 0.23$ \\
\hline IV & $6(7.32)$ & $12(13.33)$ & $12(14.63)$ & $16(33.33)$ & $2.40 \pm 0.32$ \\
\hline$\chi^{2} / \mathrm{F}$ & 22.64 & & & & 71 \\
\hline P-value & $<0.001^{\mathrm{c}}$ & & & & $<0.001^{\mathrm{d}}$ \\
\hline
\end{tabular}

Among groups, $\mathrm{P}<0.05$ was considered significant. ${ }^{\mathrm{a} D a t a}$ are presented as $\mathrm{n}(\%)$. ${ }^{\mathrm{b}}$ Data are presented as the mean \pm standard deviation. ${ }^{\mathrm{c}} \mathrm{P}$-value of the first therapeutic-target-achieving vs. normal, overweight, degree I and II obesity groups. ${ }^{\mathrm{d}} \mathrm{P}$-value of mean initial dose vs. normal, overweight, degree I and II obesity groups. The $\chi^{2}$ test was used to for the body mass index and the analysis of variance test for the mean initial dosage.

Laboratory information. Among all patients, the first TTA time of patients with liver dysfunction prior to treatment ranged from 1-7 (36.36\%) to 15-28 days (40.91\%), as compared with 8-28 days $(62.79 \%)$ in patients with normal liver function (Table II). This significant difference $(\mathrm{P}=0.019)$ between the groups demonstrated that liver function affected the first TTA time (Fig. 1D) of patients in the present study, whereas a slight decrease in ALB, mild to moderate anemia, and renal impairment did not affect the first TTA time (data not shown).

Administration of pharmacological agents. The first TTA time of patients who received cephalosporins ranged from $\leq 7(30.25 \%)$ to $15-28$ days $(36.79 \%)$, as compared with 8-28 days in patients who did not receive cephalosporins $(66.66 \%)(\mathrm{P}=0.0017)$. Moreover, the first TTA time was $\leq 7$ days $(45.83 \%)$ in patients who received levofloxacins and 15-28 days in those who did not receive levofloxacins $(39.37 \%)(\mathrm{P}<0.001)$. These results demonstrated that the administration of cephalosporins and levofloxacins affected the first TTA time (Fig. 1E) of patients in the present study, whereas the administration of penicillin antibiotics and antifungal drugs had no effect on the first TTA time (data not shown).

The following cardiovascular drugs had no effect on the first TTA time of patients enrolled in the present study: Highly selective $\beta$-blockers (metoprolol, bisoprolol), lipid-lowering statins (simvastatin, atorvastatin, and fluvastatin), diuretics (spironolactone, furosemide), calcium channel blockers (nifedipine), aspirin and angiotensin-converting enzyme inhibitors.

The first TTA time was 8-28 days in the majority (65.95\%) of patients who received blood circulation-activating drugs, whereas the majority of patients who did not receive these drugs exhibited a first TTA time of 15-28 days (35.34\%) and $>28$ days $(25 \%)$; the difference was statistically significant $(\mathrm{P}=0.001)$. These results demonstrated that blood circulation-activating drugs affected the first TTA time of patients in the present study, whereas proton pump inhibitors and adrenal cortex hormones had no effect on the first TTA time (data not shown).

In summary, univariate analysis demonstrated that the initial dose of warfarin, BMI, liver function and heart failure status of patient, and levofloxacin, cephalosporin and blood circulation-activating drug administration affected the first TTA time of patients following warfarin therapy.

Ordered logistic regression analysis. Statistically significant factors, as determined by univariate analysis, were included in ordered logistic regression analyses. As shown in Table III, the first TTA time was: i) Increased in the 2.5 and $3 \mathrm{mg}$ groups, as compared with the $5 \mathrm{mg}$ group [odds ratio $(\mathrm{OR})>1 ; \mathrm{P}<0.05$ ]; ii) decreased in the overweight and normal BMI groups, as compared with the degree II obesity group $(\mathrm{OR}<1 ; \mathrm{P}<0.05)$, with no significant difference detected between the rate of the first TTA time extension in the degree I and II obesity groups $(\mathrm{OR}=2.0, \mathrm{P}=0.269)$; iii) decreased in patients with hepatic dysfunction and heart failure $(\mathrm{OR}<1 ; \mathrm{P}<0.05)$; and iv) increased in the group that did not receive levofloxacins $(\mathrm{OR}=1.375$, $\mathrm{P}<0.05)$, with cephalosporins and blood circulation-activating drugs not identified as independent factors affecting the first TTA time $(\mathrm{OR}>1, \mathrm{P}>0.05)$.

In summary, BMI, liver function, heart failure and levofloxacin administration were identified as independent factors affecting the first TTA time of patients treated with warfarin.

Correlation analysis. Among the 302 cases examined in the present study, no significant differences in INR distribution were detected in the four first TTA time segments between patients with effective and improved anticoagulation. These results demonstrated that there was no correlation between the INR distribution according to different first TTA time segments and warfarin therapy efficacy (effective or improved) (Table IV).

Among the 302 cases, the first TTA time was 15-28 days in the majority of patients with $(41.67 \%)$ or without $(34.55 \%)$ minor bleeding, and 7-14 days (60\%) in patients with severe bleeding. As the difference was not statistically significant $(\mathrm{P}=0.673)$, these results demonstrated that there was no correlation between bleeding severity and INR distribution according to the first TTA of patients enrolled in the present study (Table IV).

Anticoagulant efficacy. Following 90 days of warfarin therapy, therapeutic anticoagulation was achieved in 71 cases, with an 
A

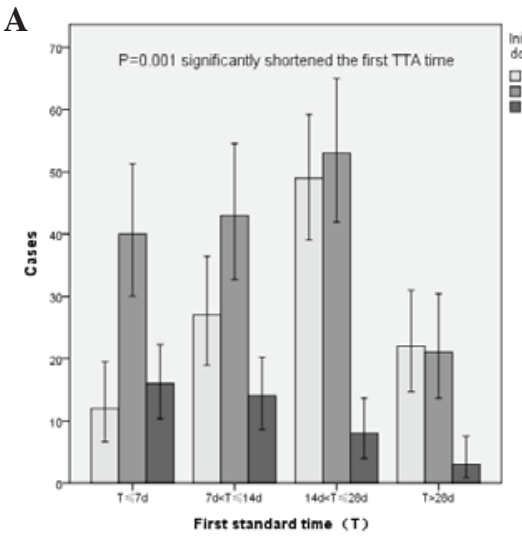

D

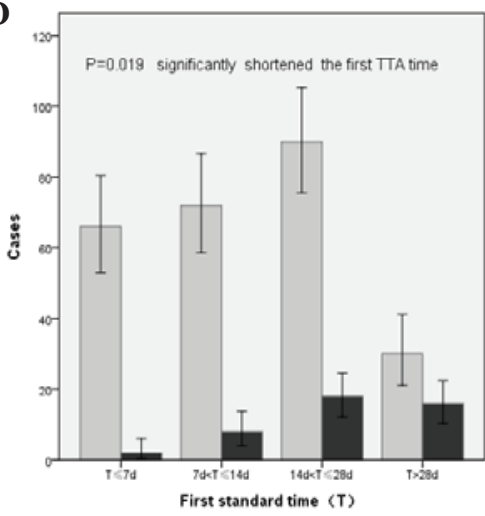

B

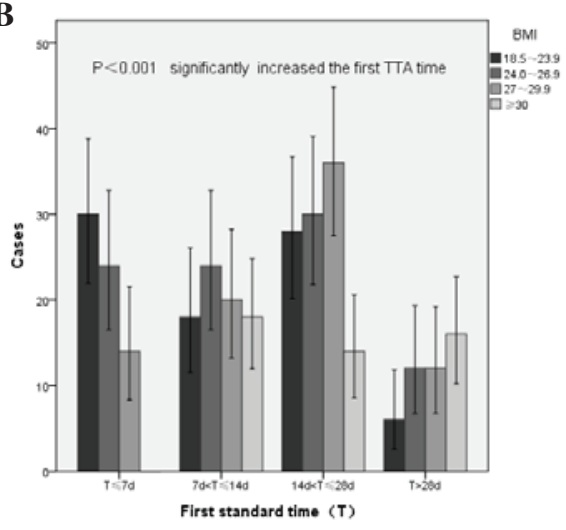

C

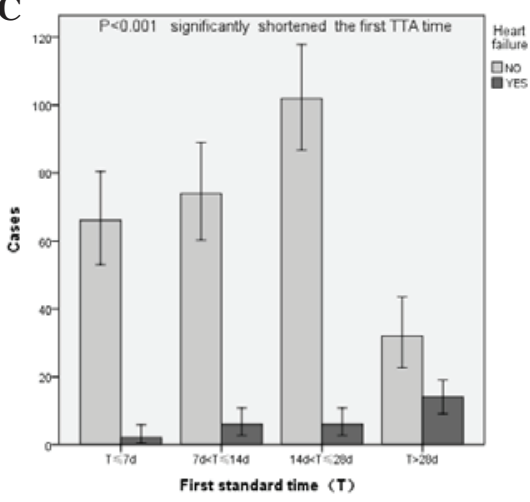

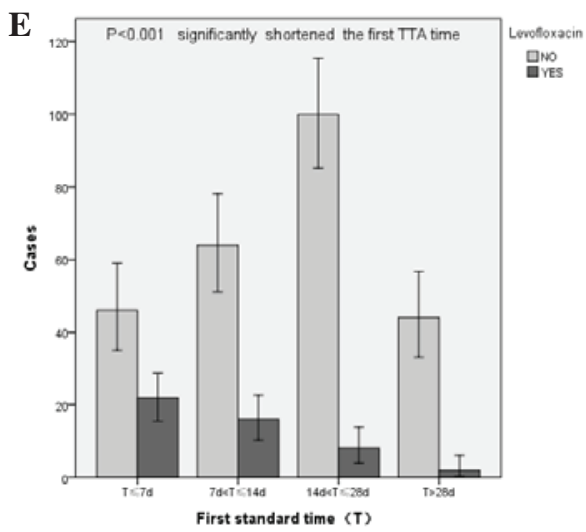

Figure 1. Single-factor statistical analysis of first therapeutic-target-achieving time. Respective associations between the first standard time and (A) initial dose, (B) body mass index (BMI), (C) heart failure incidence, (D) liver function and (E) levofloxacin administration. The $\chi^{2}$ test was used for statistical analysis.

efficacy rate of $23.4 \%$. Improved anticoagulation was achieved in 231 cases, with an improvement rate of $76.6 \%$. There were no cases of ineffective anticoagulation.

Adverse reactions. Adverse reactions included bleeding and rethrombosis. Within 90 days of warfarin therapy, bleeding occurred in 82 patients (27.15\%), which was deemed to be minor in 72 patients $(23.84 \%)$ and severe in 10 patients $(3.31 \%)$. Furthermore, rethrombosis occurred in 5 patients $(1.54 \%)$ within 90 days of warfarin therapy,.

\section{Discussion}

Although various factors are known to affect warfarin, in vivo and in vitro, it was not straightforward at home and worldwide. The results of the present study demonstrated that various factors were capable of influencing the TTA time associated with warfarin therapy in patients with PTE, including the initial dose of warfarin, BMI, liver function, heart failure status and levofloxacin administration. As only Chinese patients with PTE were included in the present study, an initial dose of $3 \mathrm{mg}$ was selected.

As outlined in the 9th edition of the Antithrombotic Therapy and Prevention of Thrombosis Guidelines, American College of Chest Physicians (ACCP9) (7), the initial dose of warfarin predominantly ranges between 5 and $10 \mathrm{mg}$, and should be selected according to the patient's sensitivity to warfarin, age, weight, intended treatment and associated complications. Furthermore, the recommended initial dose is $<5 \mathrm{mg}$ in the elderly, and patients with malnutrition, liver disease, congestive heart failure and high risk of bleeding (15). Although previous international studies (16-19) have investigated the TTA time associated with loading doses of 5 and $10 \mathrm{mg}$ warfarin and the incidence of adverse events, the conclusions were inconsistent. In a previous study conducted by Kovacs et al (16), 209 outpatients with acute venous thromboembolism were randomly assigned into two groups with initial doses of 5 and $10 \mathrm{mg}$, respectively. The results demonstrated that: i) The TTA time of the $10 \mathrm{mg}$ group was 1.4 days shorter than that of the $5 \mathrm{mg}$ group $(\mathrm{P}<0.001)$; ii) the TTA rates on day 5 in the 5 and $10 \mathrm{mg}$ groups were 83 and $46 \%$, respectively $(\mathrm{P}<0.001)$; and iii) no significant differences in the incidence rates of bleeding, re-embolism and over-anticoagulation with an INR of $>5.0$ were detected between the two groups $(\mathrm{P}=0.09)$. Farahmand et al (20) corroborated these results using the same methodology. Mahtani et al (21) performed a statistical analysis of the data from 12 previous studies, and found that there is still a considerable uncertainty between the use of a $5 \mathrm{mg}$ and a $10 \mathrm{mg}$ loading dose for the initiation of warfarin. Furthermore, Suwanawiboon et al (22) investigated the associations between various warfarin doses and first TTA time in patients with heart valve replacement, with the results demonstrating that the mean TTA time of the $2.5 \mathrm{mg}$ group was greater than that of the $5 \mathrm{mg}$ group $(\mathrm{P}<0.0001)$. Furthermore, during treatment, an INR of $>2.6$ was observed in 42.5 and $26.2 \%$ of the patients in the 5 and $2.5 \mathrm{mg}$ groups, respectively $(\mathrm{P}<0.05)$. Although there were no cases of bleeding or re-embolism, on day 3 of dose adjustment, $95.6 \%$ of patients in the $5 \mathrm{mg}$ group required 
Table II. Univariate analysis of the first therapeutic-target-achieving time and initial dosage, heart failure and liver function.

\begin{tabular}{|c|c|c|c|c|c|c|c|}
\hline \multirow[b]{2}{*}{ Group } & \multicolumn{3}{|c|}{ Initial dosage (mg) } & \multicolumn{2}{|c|}{ Heart failure } & \multicolumn{2}{|c|}{ Liver function } \\
\hline & 2.5 & 3 & 5 & No & Yes & Normal & Abnormal \\
\hline I & $12(10.81)$ & $41(26.28)$ & $15(41.67)$ & $54(19.71)$ & $14(50.00)$ & $52(20.16)$ & $16(36.36)$ \\
\hline II & $27(24.32)$ & $43(27.56)$ & $10(27.78)$ & $74(27.01)$ & $6(21.43)$ & $72(27.91)$ & $8(18.18)$ \\
\hline III & $49(44.14)$ & $51(32.69)$ & $8(22.22)$ & $102(37.23)$ & $6(21.43)$ & $90(34.88)$ & $18(40.91)$ \\
\hline IV & $23(20.72)$ & $21(13.46)$ & $3(8.33)$ & $44(16.06)$ & $2(7.14)$ & $44(17.05)$ & $2(4.55)$ \\
\hline$\chi^{2} / \mathrm{F}$ & \multicolumn{3}{|c|}{21.943} & \multicolumn{2}{|c|}{15.301} & \multicolumn{2}{|c|}{9.971} \\
\hline P-value & \multicolumn{3}{|c|}{$0.001^{\mathrm{a}}$} & \multicolumn{2}{|c|}{$<0.001^{\mathrm{b}}$} & \multicolumn{2}{|c|}{$0.019^{c}$} \\
\hline
\end{tabular}

Among groups, $\mathrm{P}<0.05$ was considered significant. Data are presented as n (\%). ${ }^{\mathrm{a}} \mathrm{P}$-value of first therapeutic-target-achieving (TTA) comparison among the $2.5,3$ and $5 \mathrm{mg}$ group. ${ }^{b} \mathrm{P}$-value of first TTA compared to the heart and no heart failure groups. ${ }^{\mathrm{C}} \mathrm{P}$-value of the first TTA compared between the normal liver and abnormal liver function groups. The $\chi^{2}$ test was used for statistical analysis.

Table III. Ordered logistic analysis of the first therapeutic-target-achieving time.

\begin{tabular}{|c|c|c|c|c|c|}
\hline \multirow[b]{2}{*}{ Indicator } & \multirow[b]{2}{*}{ OR } & \multirow[b]{2}{*}{ Wald's $\chi^{2}$} & \multirow[b]{2}{*}{ P-value } & \multicolumn{2}{|c|}{$95 \% \mathrm{CI}$ for OR } \\
\hline & & & & Lower bound & Upper bound \\
\hline \multicolumn{6}{|c|}{ Initial dosage (mg) } \\
\hline $1(2.5)$ & 4.516 & 7.547 & 0.007 & 3.511 & 5.521 \\
\hline $2(3)$ & 2.217 & 5.840 & 0.022 & 1.327 & 3.107 \\
\hline $3(5)$ & 1 & & & & \\
\hline \multicolumn{6}{|l|}{ BMI } \\
\hline $0(18.5-23.9)$ & 0.122 & 9.724 & 0.003 & 0.030 & 0.493 \\
\hline $1(24-26.9)$ & 0.208 & 5.100 & 0.024 & 0.053 & 0.813 \\
\hline $2(27-29.9)$ & 2.081 & 1.221 & 0.269 & 0.567 & 7.652 \\
\hline $3(>30)$ & 1 & & & & \\
\hline \multicolumn{6}{|l|}{ Liver function } \\
\hline 0 (abnormal) & 0.011 & 7.699 & 0.006 & 0.002 & 0.068 \\
\hline 1 (normal) & 1 & & & & \\
\hline \multicolumn{6}{|l|}{ Heart failure } \\
\hline 0 (yes) & 0.025 & 8.740 & 0.002 & 0.003 & 0.190 \\
\hline 1 (no) & 1 & & & & \\
\hline \multicolumn{6}{|c|}{ Blood circulation-activating TCM } \\
\hline 0 (not used) & 1.863 & 3.583 & 0.058 & 0.978 & 3.547 \\
\hline 1 (used) & 1 & & & & \\
\hline \multicolumn{6}{|l|}{ Cephalosporin } \\
\hline 0 (not used) & 1.818 & 3.660 & 0.056 & 0.985 & 3.353 \\
\hline 1 (used) & 1 & & & & \\
\hline \multicolumn{6}{|l|}{ Levofloxacin } \\
\hline 0 (not used) & 1.375 & 10.451 & 0.001 & 1.565 & 9.994 \\
\hline 1 (used) & 1 & & & & \\
\hline
\end{tabular}

Among groups, $\mathrm{P}<0.05$ was considered significant. Ordered logistic analysis was used for statistics. OR, odds ratio; CI, confidence interval; BMI, body mass index.

a warfarin dose reduction; whereas only $53.5 \%$ of patients in the $2.5 \mathrm{mg}$ group required warfarin dose adjustments as the INR in the $2.5 \mathrm{mg}$ group was considerably more stable. Therefore, a low loading dose of warfarin was recommended in order to reduce the occurrence of excessive anticoagulation in patients with heart valve replacement, and the requirement for dose adjustment, resulting in a stable TTA time to achieve effective anticoagulation. 


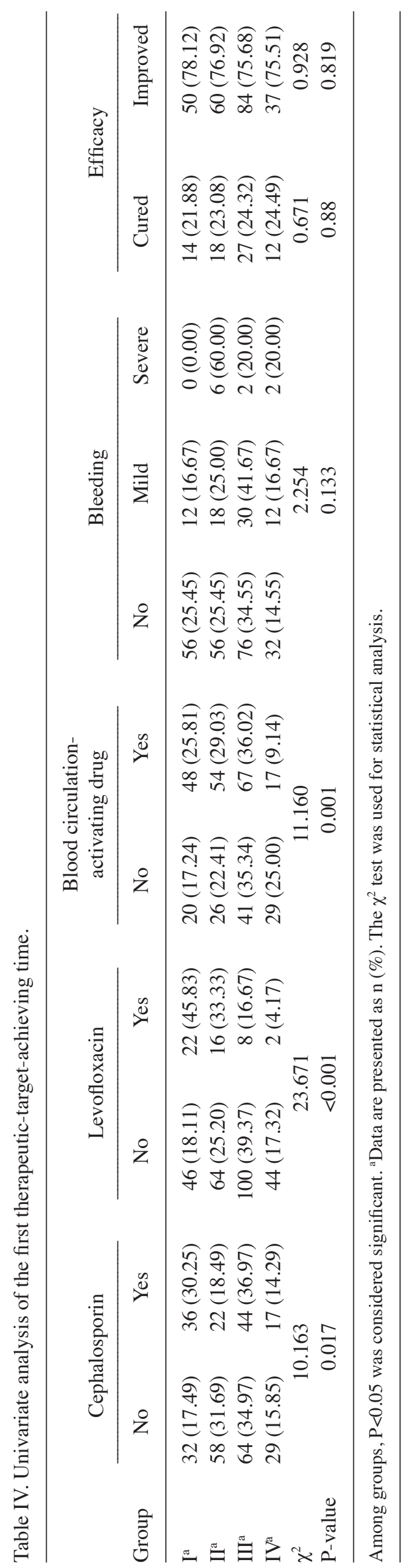

The 'Chinese Expert Consensus Towards Warfarin Anticoagulation' (23) recommends an initial dose of 1-3 mg warfarin in Chinese populations in order to reach the target range within 2-4 weeks. Thus, the recommended mean dose of warfarin is lower in Chinese patients as compared with Western populations, due to differences in hepatic drug-metabolizing enzymes. The results of the present study demonstrated that the TTA time of the $5 \mathrm{mg}$ group was the shortest, whereas that of the $2.5 \mathrm{mg}$ group was the longest, with the $3 \mathrm{mg}$ group in between the two groups $(\mathrm{P}=0.001$; a comparison of the three groups, 2.5, 3 and $5 \mathrm{mg}$ ). However, 13 patients in the $5 \mathrm{mg}$ group required repeated dosage reductions or discontinued therapy and commenced therapy with vitamin K1 (VitK) antagonists, which increased the risk of bleeding. Therefore, $3 \mathrm{mg}$ warfarin was used as the initial dose in order to ensure the first TTA was achieved safely and rapidly.

The results of the present study indicated that the first TTA time was considerably increased in obese patients, which is consistent with the results of previous studies. For example, Wallace et al (24) investigated the association between BMI and the first TTA time according to the foreign BMI classification criteria. The results of this study demonstrated that $\sim 50 \%$ of patients with low/normal weight or overweight achieved the required standards within day 6 of treatment $(\mathrm{P}<0.0001)$; whereas $50 \%$ of obese and morbidly obese patients achieved the standards on days 8 and 10 of treatment, respectively. Furthermore, TTA rates were significantly lower in the obese and morbidly obese patients, as compared with patients of a normal weight prior to discharge ( $\mathrm{P}=0.0004)$. The daily average dose of warfarin was also increased in obese patients, as compared with the patients without obesity $(\mathrm{P}<0.05)$. Therefore, Wallace et al (24) concluded that BMI was associated with the patient's sensitivity to warfarin, and could influence the warfarin dose and initial TTA time. Another previous study suggested that the reduced sensitivity of obese patients towards warfarin was due to the increased drug distribution volume in obese patients (25).

The results of the present study indicated that age and gender had no effect on the first TTA time of warfarin therapy, which is consistent with the conclusions of a previous study conducted by Roberts et al (26). However, Jensen et al (27) have previously demonstrated that the TTA time increases with age. The metabolic clearance rate of warfarin would decrease, whereas its protein-binding rate would not increase; thus, Jensen et al (27) considered that age may affect an individual's sensitivity to warfarin and first TTA time. Therefore, further studies are required to investigate this phenomenon.

The majority of previous studies have suggested that patients with decompensated heart failure may have an increased sensitivity to warfarin (28). It has been speculated that the mechanism may be associated with liver dysfunction and congestion (29). Furthermore, Hylek et al (30) described the following oxygen deficiency theory: The oxygen uptake capacity of liver cells decreases when they are damaged, as the P450-linked drug metabolism depends on oxygen supply, resulting in a decreased clearance rate of warfarin and increased blood concentration, followed by enhanced anticoagulant effects.

A previous study (31) demonstrated that when an equal dose of double-coumarin was administered, the PT values of 
the moderate to severe heart failure $(n=18)$, mild heart failure $(n=5)$ and control groups $(n=48)$ increased by 9.7, 3.8 and $2.4 \mathrm{sec}$, respectively $(\mathrm{P}<0.05)$. Therefore, it was speculated that the severity of heart failure was positively correlated with the effect of coumarin metabolism. Warfarin is a type of coumarin, and coumarin is a class of drugs that has a similar effect. Furthermore, a previous study (32) have demonstrated that patients with various degrees of heart failure are capable of achieving the standards within $24 \mathrm{~h}$ of low-dose warfarin therapy, with certain patients failing to meet the standards with high-dose warfarin therapy, which is not consistent with the conclusions of previous studies $(33,34)$. The present study suggested that the TTA time of patients with heart failure was significantly decreased, as compared with patients without heart failure. As the sample size of patients with heart failure was small and heart failure was not classified according to the cardiac ejection fraction in the present study, further studies are required in order to confirm the effects of heart failure severity on the first TTA time.

Polycyclic aromatic hydrocarbons produced by the incomplete combustion of cigarette smoke may induce the activities of hepatic microsomal enzymes, including cytochrome 1A1 (CYP1A1), cytochrome 1A2 (CYP1A2) and cytochrome 2E1 (CYP2E1), which increases the clearance rate of warfarin and mitigates its anticoagulant effects $(35,36)$. To date, the effect of smoking on the first TTA time remains uncertain. A prior study (37) have demonstrated that the drug distribution volume, steady-state level and half-life of warfarin were increased by 11,13 and $23 \%$ following smoking cessation, whereas the clearance rate decreased by $13 \%$. Other studies $(38,39)$ have suggested that the use of warfarin in smokers is associated with an increased INR following smoking cessation. By contrast, McGriff-Lee et al (40) suggested that smoking was not correlated with INR changes following warfarin therapy. The results of the present study demonstrated that the first TTA time in smokers was significantly increased, as compared with the non-smokers $(\mathrm{P}=0.107)$, and that smoking had no effect on INR changes.

Although the 9th Edition Guideline of ACCP (7) considered that long-term alcohol intake may increase the metabolic clearance rate of warfarin, the 21-day heavy liquor intake (alcohol volume, $47.36 \mathrm{~g} / \mathrm{day}$ ) of healthy volunteers exhibited minimal alterations in PT values, which is consistent with the conclusion of the present study that alcohol intake had no effect on the first TTA time of warfarin.

The liver is responsible for synthesizing ALB and clotting factors, in addition to metabolizing drugs. Previous studies have demonstrated that liver disease may result in a high INR, suggesting that liver dysfunction may affect the first TTA time of warfarin and increase the incidence of excessive anticoagulation (41). The results of the present study demonstrated that the first TTA time was significantly reduced in patients with liver dysfunction, as compared with subjects with normal liver function $(\mathrm{P}=0.019)$, which may increase the INR value; this is consistent with the results of a previous study by Denas et al (42). Furthermore, Abe et al (43)demonstrated that long-term warfarin therapy in patients with end-stage renal disease (ESRD) resulted in a significantly higher binding rate of warfarin and ALB post-hemodialysis, as compared with pre-hemodialysis. However, the INR value was reduced, which suggests that the ALB levels were negatively correlated with INR changes, which was an important factor. Therefore, these findings suggest that it is important to adjust the initial doses of warfarin and closely monitor INR values in patients with impaired liver function.

Previous human and animal experiments $(44,45)$ have indicated that the metabolic functions of the liver enzyme P450 were reduced by $40-85 \%$ in patients with ESRD, which resulted in reduced clearance rates of non-renal metabolized drugs, including warfarin, and an increased area under the curve. Furthermore, consistent with plasma total protein and ALB, patients with renal dysfunction exhibited $\leq 2$-fold increases in free warfarin, as compared with healthy subjects. Therefore, ESRD may affect the metabolism of non-renal-pathway drugs by decreasing the metabolic functions of the liver enzyme P450 and reducing drug-protein binding, distribution volume and acid-base balance. Limdi et al (46) have previously demonstrated that in order to achieve the same intensity of anticoagulation, patients with moderate to severe renal insufficiency require lower doses of warfarin, as compared with patients with no or mild renal insufficiency (10-20\%), and the TTA time was also significantly reduced. Sakaan et al (47) identified that chronic kidney disease and ESRD patients require $20 \%$ lower warfarin doses to maintain a therapeutic INR, and may require less time to achieve a therapeutic INR compared with patients with normal kidney function. In the present study, Ccr could not be used to comprehensively evaluate renal function as it only represents the glomerular filtration rate; therefore, only cases with mild to moderate renal insufficiency were included. The results of the present study suggested that normal renal function and mild to moderate renal insufficiency may not affect the first TTA time associated with warfarin therapy.

Warfarin is composed of two different active R-isomer and S-isomers, which are metabolized by different P450 liver enzymes (48). R-warfarin is metabolized by CYP1A2 and cytochrome 3A4 (CYP3A4), whereas S-warfarin is metabolized by cytochrome P450 2C9 (CYP2C9) (48). R-warfarin may affect the activities of S-warfarin metabolic enzyme; thus, the induction or inhibition of warfarin metabolic enzymes may weaken or strengthen the anticoagulant effects of warfarin (48). Furthermore, the efficacy of warfarin may be affected by altering the bioavailability of VitK, undermining the absorption of warfarin, affecting the synthesis and metabolism of VitK-dependent coagulation factors, and changing the receptor affinities, which may lead to bleeding and re-embolism (48).

The 9th ACCP guidelines (7) suggested that antifungal drugs such as quinolones, sulfonamides, macrolides and pyrroles, may markedly enhance the anticoagulant effect of warfarin, and amoxicillin and cephalosporins may only moderately enhance its anticoagulant effect. The underlying mechanisms of antibacterial drugs associated with the anticoagulant effect of warfarin were as follows: (i) Competitively binding the plasma proteins, thus increasing the concentrations of active free warfarin; ii) inhibiting VitK synthesis by the intestinal flora, thus reducing the generation of VitK-dependent coagulation factors; and iii) inhibiting the activities of cytochrome P450 enzyme, thus reducing the clearance rate of warfarin and enhancing its anticoagulant effects. 
To date, a limited number of studies (49-52) have investigated the impact of levofloxacin on the first TTA time and the results of these studies remain controversial. Glasheen et al (49) demonstrated that the INR values of warfarin users increased by 0.85 when treated with levofloxacin $(\mathrm{P}<0.05)$, and the incidence rate of excessive anticoagulation (INR, $>4)$ was $19 \%(\mathrm{P}<0.05$ vs. terazosin), which was consistent with the results of a study conducted by Lane et al (50). Another previous study (51) demonstrated that, when warfarin users were administered levofloxacin, the INR values of $44 \%$ of patients were increased beyond the therapeutic range and the doses required adjustment. The INR values of $17 \%$ of patients were increased by $\sim 1.0$, and $11 \%$ of patients exhibited INR values $>4.0$. These results suggested that levofloxacin administration affected the anticoagulant efficacy of warfarin and was capable of significantly increasing INR values and decreasing the first TTA time, which was consistent with the conclusions of the other two studies $(49,50)$. Yamreudeewong et al (52) observed no significant changes in the INR of warfarin users who were administered levofloxacin for 5-10 days were prior to and following follow-up (2.61 \pm 0.44 vs $2.74 \pm 0.83 ; \mathrm{P}=0.419)$. Therefore, Yamreudeewong et al (52) concluded that levofloxacin did not affect the anticoagulant effect of warfarin. This pharmacokinetic study also demonstrated that quinolones did not affect the pharmacokinetics of warfarin.

As there are a wide range of cephalosporins with variable chemical structures and pharmacokinetics, there were notable differences in the impact on the INR values (53-55). For example, cephalosporins with a sulfur-methyl tetrazole side chain, including cefmenoxime, cefamandole, cefminox and cefoperazone, are capable of interfering with VitK circulation, thus inhibiting the synthesis of prothrombin (48). Furthermore, a previous study (56) have demonstrated that cefamandole, which contains the sulfur-methyl tetrazole side chain, is capable of inducing prothrombin time (PT) to prolong and decrease the activities of factor VII; whereas ceftazidime had no effect on these two parameters. Univariate analysis performed in the present study demonstrated that cephalosporin had no effect on the first TTA time; however, this was not confirmed in the ordered logistic analysis.

In summary, antimicrobial drugs may affect the anticoagulant effects of warfarin and increase INR values; thus, in order to prevent adverse reactions, INR monitoring is required when warfarin is administered in combination with antimicrobial drugs.

Among the lipid-lowering statins, fluvastatin, simvastatin and atorvastatin are CYP3A4 inhibitors (57); however, they demonstrated varying effects of enhancing the anticoagulation intensity of warfarins. Fluvastatin is a CYP3A4 inhibitor, and following CYP2C9 metabolism has been demonstrated to significantly enhance the anticoagulant effect of warfarin (57). Following the metabolism of CYP3A4, simvastatin was capable of reducing the clearance rate of R-warfarin, resulting in a significant increase in the anticoagulant effect of warfarin by simvastatin, and a 1.25-fold increased in the INR value (58). The metabolic rate of atorvastatin by CYP3A4 was lower than that of simvastatin; therefore, the enhanced effect of warfarin rapidly subsided (48).

The present study indicated that glucocorticoids may increase the risk of thrombosis, whereas the results regarding anticoagulation when warfarin was combined with other pharmacological agents were inconsistent. A previous study (59) suggested that corticosteroids may reduce the anticoagulant effects of warfarin. However, Costedoat-Chalumcau et al (60) demonstrated that, when combined with an intravenous infusion of $500 \mathrm{mg}$ or $1 \mathrm{~g}$ methylprednisolone for $>1 \mathrm{~h}$, INR may increase to 8.04 (5.32-20), whereas no significant changes in INR were detected in the methylprednisolone-treated control group. Therefore, Costedoat-Chalumcau et al (60) concluded that a large dose of methylprednisolone was capable of enhancing the anticoagulant effect of warfarin and increasing the risk of bleeding. Although the interaction mechanism remains undetermined, previous studies $(61,62)$ have suggested that methylprednisolone reduces the clearance rate of warfarin by inhibiting the liver enzyme P450.

In the present study, the active ingredients of the blood circulation-activating drugs were predominantly ginkgo, angelica and salvia (63), which were demonstrated to reduce the clearance rate of warfarin and enhance its anticoagulant effect, resulting in increased INR values. These active ingredients also inhibited platelet aggregation and increased blood clotting enzyme factor III and fibrinolytic activity. Furthermore, angelica contains coumarin derivatives, which could complement the anticoagulant effects of warfarin and prolong PT (64). Ginkgo preparation (31) could inhibit platelet activating factors to reduce platelet aggregation, although its combination with warfarin may increase the risk of bleeding.

A potential limitation of the present study was the failure to investigate different countries with different populations. Although evaluation of this information was desirable, this was precluded by a variety of problems including the need for case collection, cost considerations and a lack of researchers. However, the initial aim was to assess the factors in the Chinese population, with future studies investigating different countries with additional populations in order to expand the scope of the present study.

In conclusion, various factors affect the first TTA time associated with warfarin therapy, and these factors should be carefully considered during clinical treatment with warfarin. The results of the present study suggested that a high initial dose, increased BMI, hepatic dysfunction, heart failure and levofloxacin administration may reduce the first TTA time associated with warfarin therapy. Therefore, the initial dose of warfarin should be evaluated on a individual basis, based on various factors including the patient's BMI, liver function and the presence of heart failure, in order to ensure the efficacy of anticoagulation, and other reasonable pharmacological agents should be considered to facilitate prompt and safe standard achievements.

\section{Acknowledgements}

This study was supported by Hebei Province Administration of Scientific Research of Traditional Chinese Medicine Fund Project (grant no. 2016045) and theNatural Science Foundation of Hebei Province of China (grant no. H2013206403).

\section{References}

1. Stein PD and Matta F: Epidemiology and incidence: The scope of the problem and risk factors for development of venous thromboembolism. Crit Care Clin 27: 907-932, 2011. 
2. Stein PD, Matta F, Keyes DC and Willyerd GL: Impact of vena cava filters on in-hospital case fatality rate from pulmonary embolism. Am J Med 125: 478-484, 2012.

3. Stein PD and Matta F: Thrombolytic therapy in unstable patients with acute pulmonary embolism: Saves lives but underused. Am J Med 125: 465-470, 2012.

4. Stein PD and Matta F: Case fatality rate with pulmonary embolectomy for acute pulmonary embolism. Am J Med 125 471-477, 2012.

5. Agnelli G, Buller HR, Cohen A, Curto M, Gallus AS, Johnson M, Porcari A, Raskob GE and Weitz JI; PLIFY-EXT Investigators: Apixaban for extended treatment of venous thromboembolism. N Engl J Med 368: 699-708, 2013.

6. Schulman S, Kearon C, Kakkar AK, Schellong S, Eriksson H, Baanstra D, Kvamme AM, Friedman J, Mismetti P, Goldhaber SZ, et al: Extended use of dabigatran, warfarin, or placebo in venous thromboembolism. N Engl J Med 368 709-718, 2013.

7. Holbrook A, Schulman S, Witt DM, Vandvik PO, Fish J, Kovacs MJ, Svensson PJ, Veenstra DL, Crowther M and Guyatt GH; American College of Chest Physicians: Evidence-based management of anticoagulant therapy: Antithrombotic therapy and prevention of thrombosis, 9th ed: American college of chest physicians evidence. Based Clin Pract Guidelines 141 (Suppl 2): e152S-e184S, 2012.

8. Keeling D, Baglin T, Tait C, Watson H, Perry D, Baglin C, Kitchen S and Makris M; British Committee for Standards in Haematology: Guidelines on oral anticoagulation with warfarin-fourth edition. Br J Haematol 154: 311-324, 2011.

9. Navgren M, Forsblad J and Wieloch M: Bleeding complications related to warfarin treatment: A descriptive register study from the anticoagulation clinic at Helsingborg hospital. J Thromb Thrombolysis 38: 98-104, 2014.

10. Nelson WW, Choi JC, Vanderpoel J, Damaraju CV, Wildgoose P, Fields LE and Schein JR: Impact of co-morbidities and patient characteristics on international normalized ratio control over time in patients with nonvalvular atrial fibrillation. Am J Cardiol 112: 509-512, 2013.

11. Gallego P, Roldán V, Marin F, Gálvez J, Valdés M, Vicente V and Lip GY: SAMe-TT2R2 score, time in therapeutic range, and outcomes in anticoagulated patients with atrial fibrillation. Am J Med 127: 1083-1088, 2014.

12. Grzymala-Lubanski B, Labaf A, Englund E, Svensson PJ and Själander A: Mechanical heart valve prosthesis and warfarin-treatment quality and prognosis. Thromb Res 133: 795-798, 2014.

13. Hylek EM: Vitamin $\mathrm{K}$ antagonists and time in the therapeutic range: Implications, challenges and strategies for improvement. J Thromb Thrombolysis 35: 333-335, 2013.

14. Ageno W, Turpie AG, Steidl L, Ambrosini F, Cattaneo R, Codari RL, Nardo B and Venco A: Comparison of a daily fixed 2.5-mg warfarin dose with a 5-mg, international normalized ratio adjusted, warfarin dose initially following heart valve replacement. Am J Cardiol 88: 40-44, 2001.

15. Schulman S, Beyth RJ, Kearon C, Levine MN; American College of Chest Physicians: Hemorrhagic complications of anticoagulant and thrombolytic treatment: American College of Chest Physicians Evidence Based Clinical Practice Guidelines (8th Edition). Chest 133 (6 Suppl): S257-S298, 2008.

16. Kovacs MJ, Rodger M, Anderson DR, Morrow B, Kells G, Kovacs J, Boyle E and Wells PS: Comparison of 10-mg and 5-mg warfarin initiation nomograms together with low molecular weight heparin for outpatient treatment of acute venous thromboembolism. A randomized, double-blind, controlled trial. Ann Intern Med 138: 714-719, 2003.

17. Garcia P, Ruiz W and Loza Munárriz C: Warfarin initiation nomograms for venous thromboembolism. Cochrane Database Syst Rev 29: CD007699, 2016.

18. Garcia P, Ruiz W and Loza Munarriz C: Warfarin initiation nomograms for venous thromboembolism. Cochrane Database Syst Rev 10: CD007699, 2013.

19. Mahtani KR, Heneghan CJ, Nunan D, Bankhead C, Keeling D, Ward AM, Harrison SE, Roberts NW, Hobbs FD and Perera R: Optimal loading dose of warfarin for the initiation of oral anticoagulation. Cochrane Database Syst Rev 12: CD 008685 , 2012.

20. Farahmand S, Saeedi M, Seyed Javadi HH and Khashayar P: High doses of warfarin are more beneficial than its low doses in patients with deep vein thrombosis. Am J Emerg Med 29: 1222-1226, 2011.
21. Mahtani KR, Heneghan CJ, Nunan D, Bankhead C, Keeling D, Ward AM, Harrison SE, Roberts NW, Hobbs FD and Perera R: Optimal loading dose of warfarin for the initiation of oral anticoagulation. Cochrane Database Syst Rev 12: CD008685, 2012.

22. Suwanawiboon B, Kongtim P, Chinthammitr Y, Ruchutrakool T and Wanachiwanawin $\mathrm{W}$ : The efficacy of 3-mg warfarin initiating dose in adult Thai patients, who required long-term anticoagulant therapy. J Med Assoc Thai 94 (Suppl 1): S225-S231, 2011.

23. Hu DY and Sun YH: Chinese Expert Consensus of warfarin anticoagulant therapy. Zhong Hua Nei Ke Za Zhi 1: 76-82, 2013 (In Chinese).

24. Wallace JL, Reaves AB, Tolley EA, Oliphant CS, Hutchison L, Alabdan NA, Sands CW and Self TH: Comparison of initial warfarin response in obese patients versus non-obese patients. J Thromb Thrombolysis 36: 96-101, 2013.

25. Mueller JA, Patel T, Halawa A, Dumitrascu A and Dawson NL: Warfarin dosing and body mass index. Ann Pharmacother 48: 584-588, 2014.

26. Roberts GW, Helboe T, Nielsen CB, Gallus AS, Jensen I, Cosh DG and Eaton VS: Assessment of an age-adjusted warfarin initiation protocol. Ann Pharmacother 37: 799-803, 2003.

27. Jensen BP, Chin PK, Roberts RL and Begg EJ: Influence of adult age on the total and free clearance and protein binding of (R)-and (S)-warfarin. Br J Clin Pharmacol 74: 797-805, 2012

28. Van Spall HG, Wallentin L, Yusuf S, Eikelboom JW, Nieuwlaat R, Yang S, Kabali C, Reilly PA, Ezekowitz MD and Connolly SJ: Variation in warfarin dose adjustment practice is responsible for differences in the quality of anticoagulation control between centers and countries: An analysis of patients receiving warfarin in the randomized evaluation of long-term anticoagulation therapy (RE-LY) trial. Circulation 126: 2309-2316, 2012.

29. Self TH, Reaves AB, Oliphant CS and Sands C: Does heart failure exacerbation increase response to warfarin? A critical review of the literature. Curr Med Res Opin 22: 2089-2094, 2006.

30. Hylek EM, Regan S, Go AS, Hughes RA, Singer DE and Skates SJ: Clinical predictors of prolonged delay in return of the international normalized ratio to within the therapeutic range after excessive anticoagulation with warfarin. Ann Intern Med 135: 393-400, 2001.

31. Szabó B, Merkely B and Takács I: The role of vitamin D in the development of cardiac failure. Orv Hetil 150: 1397-1402, 2009 (In Hungarian)

32. Anderson GM and Hull E: The use of dicumarol as an adjunct to the treatment of congestive heart failure; results in a controlled series of 61 cases. South Med J 41: 365-371, 1948.

33. Cotlove E and Vorzimer JJ: Serial prothrombin estimations in cardiac patients; diagnostic and therapeutic implications; use of dicumarol. Ann Intern Med 24: 648-665, 1946.

34. Wishart JH and Chapman CB: Dicoumarol therapy in congestive heart failure. N Engl J Med 239: 701-704, 1948.

35. Nathisuwan S, Dilokthornsakul P, Chaiyakunapruk N, Morarai T, Yodting $\mathrm{T}$ and Piriyachananusorn N: Assessing evidence of interaction between smoking and warfarin: a systematic review and meta-analysis. Chest 139: 1130-1139, 2011.

36. Bachmann K, Shapiro R, Fulton R, Carroll FT and Sullivan TJ: Smoking and warfarin disposition. Clin Pharmacol Ther 25: 309-315, 1979.

37. Kim MJ, Nafziger AN, Kashuba AD, Kirchheiner J, Bauer S, Gaedigk A and Bertino JS Jr: Effects of fluvastatin and cigarette smoking on CYP2C9 activity measured using the probe S-warfarin. Eur J Clin Pharmacol 62: 431-436, 2006.

38. Jordan SD, Stone MD, Alexander E, Haley J and McKee A: Patient case: Impact of smoking cessation on international normalized ratio. J Pharm Pract 27: 470-473, 2014

39. Colucci VJ and Knapp JF: Increase in international normalized ratio associated with smoking cessation. Ann Pharmacother 35 385-386, 2001.

40. McGriff-Lee NJ, Csako G, Chen T, Dang DK, Rosenfeld KG, Cannon RO, Macklin LR and Wesley RA: Anticoagulation working group: Search for predictors of nontherapeutic INR results with warfarin therapy. Ann Pharmacother 39: 1996-2002, 2005.

41. Takikawa Y, Harada M, Wang T and Suzuki K: Usefulness and accuracy of the international normalized ratio and activity percent of prothrombin time in patients with liver disease. Hepatol Res 44: 92-101, 2014

42. Denas G, Marzot F, Offelli P, Stendardo A, Cucchini U, Russo R, Nante G, Iliceto $S$ and Pengo V: Effectiveness and safety of a management protocol to correct over-anticoagulation with oral vitamin K: A retrospective study of 1,043 cases. J Thromb Thrombolysis 27: 340-347, 2009. 
43. Abe M, Maruyama N, Suzuki H, Okada K and Soma M: International normalized ratio decreases after hemodialysis treatment in patients treated with warfarin. J Cardiovasc Pharmacol 60: 502-507, 2012.

44. Dreisbach AW, Japa S, Gebrekal AB, Mowry SE, Lertora JJ, Kamath BL and Rettie AE: Cytochrome P4502C9 activity in end-stage renal disease. Clin Pharmacol Ther 73: 475-477, 2003.

45. Arnason B, Matthisson J and Madsen H: Can acute renal insufficiency increase the effect of warfarin? Ugeskr Laeger 171: 1012, 2009 (In Danish).

46. Limdi NA, Limdi MA, Cavallari L, Anderson AM, Crowley MR, Baird MF, Allon M and Beasley TM: Warfarin dosing in patients with impaired kidney function. Am J Kidney Dis 56: 823-831, 2010

47. Sakaan SA, Hudson JQ, Oliphant CS, Tolley EA, Cummings C, Alabdan NA and Self TH: Evaluation of warfarin dose requirements in patients with chronic kidney disease and end-stage renal disease. Pharmacotherapy 34: 695-702, 2014.

48. Ageno W, Gallus AS, Wittkowsky A, Crowther M, Hylek EM, Palareti G; American College of Chest Physicians: Oral anticoagulant therapy: Antithrombotic therapy and prevention of thrombosis, 9th edition, American College of Chest Physicians Evidence-Based Clinical Practice Guidelines. Chest 141 (2 Suppl): e44S-88S, 2012.

49. Glasheen JJ, Fugit RV and Prochazka AV: The risk of overanticoagulation with antibiotic use in outpatients on stable warfarin regimens. J Gen Intern Med 20: 653-656, 2005.

50. Lane MA, Zeringue A and McDonald JR: Serious bleeding events due to warfarin and antibiotic co-prescription in a cohort of veterans. Am J Med 127: 657-663, 2014

51. Glasheen JJ, Fugit RV and Prochazka AV: Effect of levofloxacin co-coadministration on the international normalized ratios during warfarin therapy-a comment. Pharmacotherapy 23 1079-1080, 2003.

52. Yamreudeewong W, Lower DL, Kipatrick DM, Enlow AM Burrows MM and Greenwood MC: Effect of levofloxacin coadministration on the international normalized ratios during warfarin therapy. Pharmacotherapy 23: 333-338, 2003.

53. Clark NP, Delate T, Riggs CS, Witt DM, Hylek EM, Garcia DA, Ageno W, Dentali F, Crowther MA; Warfarin-Associated Research Projects and Other Endeavors Consortium: Warfarin interactions with antibiotics in the ambulatory care setting. JAMA Intern Med 174: 409-416, 2014.
54. Lane MA, Zeringue A and McDonald JR: Serious bleeding events due to warfarin and antibiotic co-prescription in a cohort of veterans. Am J Med 127: 657-663, 2014.

55. Holbrook AM, Pereira JA, Labiris R, McDonald H, Douketis JD, Crowther M and Wells PS: Systematic overview of warfarin and its drug and food interactions. Arch Intern Med 165: 1095-1106, 2005.

56. Berkovitch M, Segal-Socher I, Greenberg R, Bulkowshtein M, Arnon J, Merlob P and Or-Noy A: First trimester exposure to cefuroxime: A prospective cohort study. Br J Clin Pharmacol 50: $161-165,2000$.

57. Schelleman H, Bilker WB, Brensinger CM, Wan F, Yang YX and Hennessy S: Fibrate/statin initiation in warfarin users and gastrointestinal bleeding risk. Am J Med 123: 151-157, 2010.

58. Hickmott H, Wynne $\mathrm{H}$ and Kamali F: The effect of simvastatin co-medication on warfarin anticoagulation response and dose requirements. Thromb Haemost 89: 949-950, 2003.

59. Cosgriff SW, Diefenbach AF and Vogt W Jr: Hypercoagulability of blood associated with ACTH and cortisone therapy. Am J Med 9: 752-756, 1950.

60. Costedoat-Chalumcau N, Amoura Z, Aymard G, Sevin O, Wechsler B, Cacoub P, Du LT, Diquet B, Ankri A and Piette JC: Potentiation of vitamin $\mathrm{K}$ antagonists by high-dose intravenous methylprednisolone. Ann Intern Med 132: 631-635, 2000.

61. Kaufman M: Treatment of multiple sclerosis with high-dose corticosteroids may prolong the prothrombin time to dangerous levels in patients taking warfarin. Mult Scler 3: 248-249, 1997.

62. Brigden ML, Kay C, Le A, Graydon C and McLeod B: Audit of the frequency and clinical response to excessive oral anticoagulation in an out-patient population. Am J Hematol 59: 22-27, 1998.

63. Ge B, Zhang Z and Zuo Z: Updates on the clinical evidenced herb-warfarin interactions. Evid Based Complement Alternat Med 2014: 957362, 2014.

64. Milić N, Milosević N, Golocorbin Kon S, Bozić T, Abenavoli L and Borrelli F: Warfarin interactions with medicinal herbs. Nat Prod Commun 9: 1211-1216, 2014. 